\title{
Metal-Organic Frameworks as Precursor for Metal Oxide Nanostructures Part I: MOF-Derived Copper Oxide Embedded in Carbon Matrix
}

\author{
Chinyere A. Anyamaa, Providence B. Ashishiea, Bassey E. Inaha, Idongesit J. Mbonu ${ }^{b}$, Ayi A. Ayia,*
}

\begin{tabular}{|c|c|}
\hline ART I CLE I NFO & A B S T RACT \\
\hline $\begin{array}{l}\text { K E Y W O R D S } \\
\text { Metal-organic frameworks } \\
\text { Metal oxides } \\
\text { Nanostructures } \\
\text { Hydrothermal synthesis } \\
\text { Spectral studies } \\
\text { Carbon matrix }\end{array}$ & 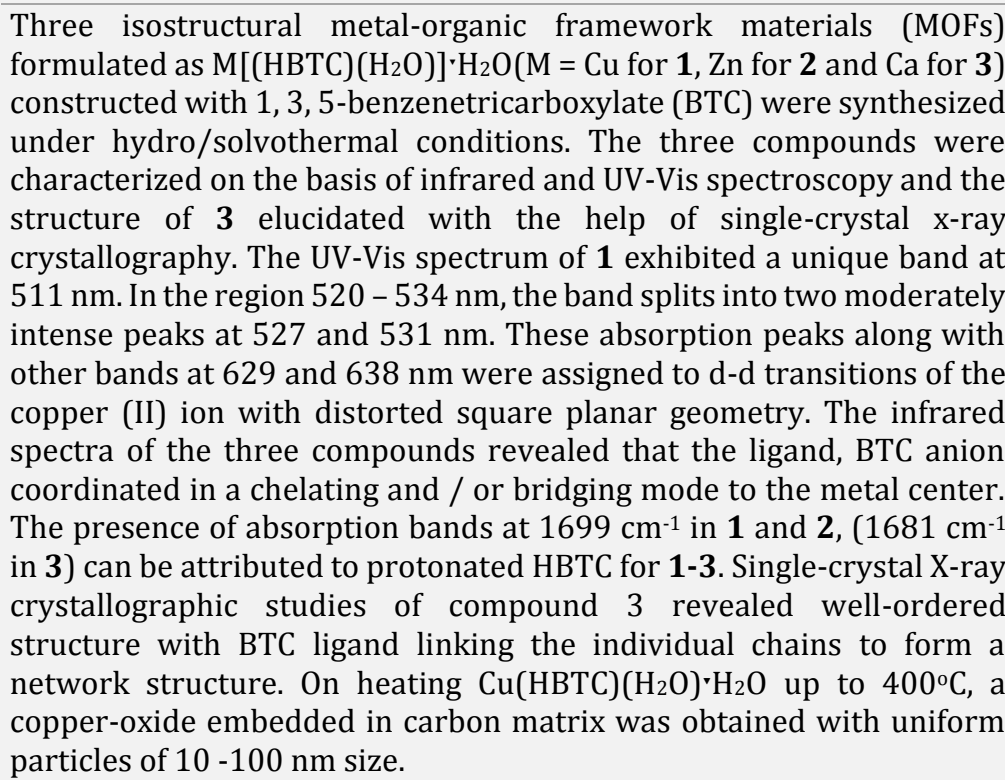 \\
\hline
\end{tabular}

GRA P H I C A L ABSTRACT

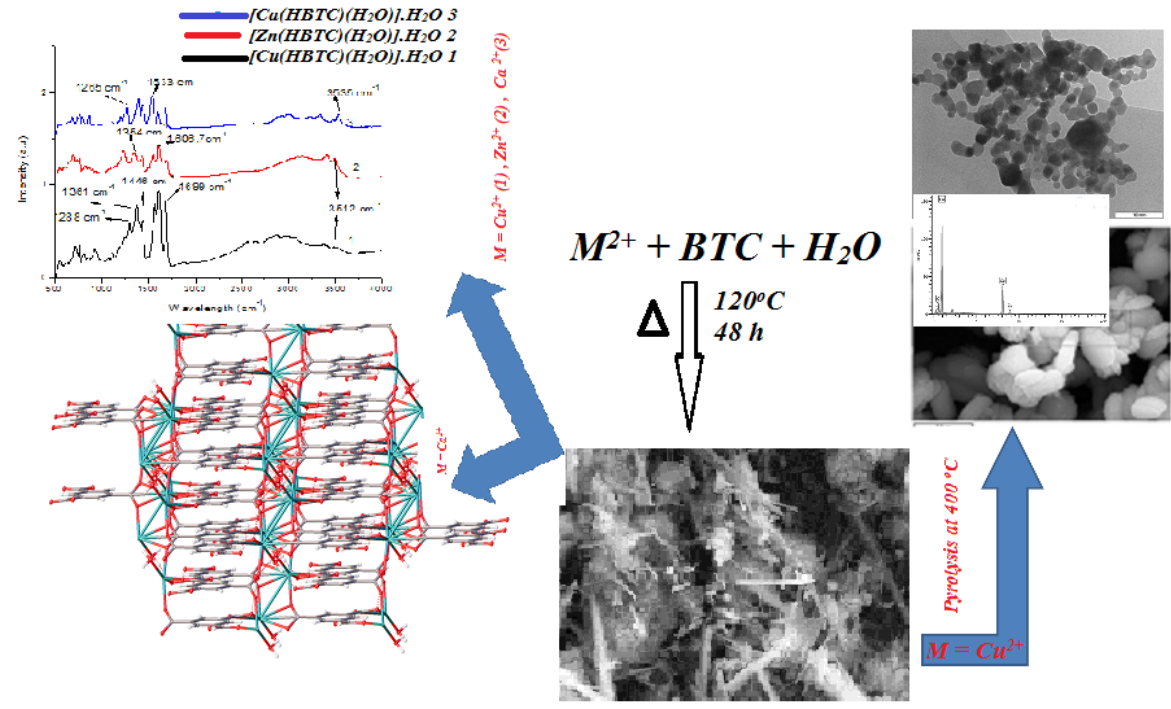

\footnotetext{
* Corresponding author's E-mail address: ayiayi72@gmail.com, a.anyama@unical.edu.ng, Tel.: +2348035961521

a Inorganic Materials Research Laboratory, Department of Pure \& Applied Chemistry, University of Calabar, Nigeria

b Department of Chemistry, Federal University of Petroleum Resources, Effurum, Nigeria
} 


\section{Introduction}

Nanotechnology involves the study of the synthesis, characterization, and properties of nanomaterials [1]. The emergence of nanotechnology has led to innovations in many areas of electronics, energy management, structural materials, functional surfaces, construction, information technology, pharmaceuticals, and medical devices. The largest share of the manufacturing and application market among the different nanomaterials belongs to metal oxide nanomaterials, they are already used in some consumer products, such as $\mathrm{TiO}_{2}$ in paints and $\mathrm{ZnO}$ in sunscreen products [2]. Metal oxides play a very important role in many areas of chemistry, physics and materials science [3-6]. The metal elements are able to form a large diversity of oxide compounds. These can adopt a vast number of structural geometries with an electronic structure that can exhibit metallic, semiconductor or insulator character. In technological applications, oxides are used in the fabrication of microelectronic circuits, sensors, piezoelectric devices, fuel cells, coatings for the passivation of surfaces against corrosion, and as catalysts. In the emerging field of nanotechnology, the goal is to make nanostructures or Nano-arrays with special properties with respect to those of bulk or single particle species [7-9]. Oxide nanoparticles can exhibit unique physical and chemical properties due to their limited size and a high density of corner or edge surface sites.

The first requirement of any novel study of nanostructured oxides is the synthesis of the material. Different synthetic protocols which have been developed in the synthesis of nanostructured metal oxides include amongst others co-precipitation, sol-gel and micro-emulsion techniques, solvo/ hydrothermal as well as using MOFs as a precursor and/or template to prepare metal or metal oxide nanoparticles inside carbon framework $[10,11]$.

In spite of the extensive research work on the preparation of metal or metal oxides nanostructures, aggregation of the particles is still a major challenge. In order to resolve the aggregation issue, a new strategy has been developed in which these nanoparticles are dispersed into carbon matrices such as porous carbon, carbon nanotubes and graphenes [12]. The carbon matrices, in addition to preventing aggregation of the nanoparticles, can also modify their properties [13].

In the design of metal-organic frameworks, versatile carboxylate ligands, such as 1,4benzenedicarboxylic acid, 1,3,5-benzenetricarboxylic acid, 1,2,4,5-benzenetetracarboxylic acid or pyridine-2,4-dicarboxylic 
acid, are usually employed under hydrothermal and/or solvo thermal conditions owing to their abundant carboxylate groups, with high affinity to metal cations [14, 15]. Metal-organic framework materials (MOFs) have been known for their applications in the area of gas storage and separation owing to their large surface area [16, 17]. In addition, MOFs have also been used in recent times, as a precursor for metal/metal oxide nanoparticle-embedded carbon frameworks $[18-22,28]$. The subject has become of particular interest for functional applications such as catalysis, gas storage materials, anode materials for lithium-ion batteries, etc. After the report on the carbonization of MOF-5, various methods have been reported to synthesize materials that contain metal/metal oxide nanoparticle-embedded porous carbon matrix from MOF precursors. In this work, Ca-, $\mathrm{Zn}$ - and Cu-carboxalye-framework solids have been prepared and characterized. The Cu-carboxylate framework was then heated under air to convert it to copper oxide nanostructures embedded in the carbon matrix. Herein, we report the copper oxide nanoparticles derived from copper carboxylateframeworks.

\section{Experimental}

\section{Materials}

The syntheses were carried out in Ace pressure tubes $\left(15 \mathrm{~cm}^{3}\right)$, purchased from Aldrich Chemical Co., and heated in programmable ovens. The reagents used for syntheses: 1, 3, 5-benzenetricarboxylic acid, 4, 4-bipyridine (Bipy), $\mathrm{Cu}\left(\mathrm{NO}_{3}\right)_{2} \cdot 2.5 \mathrm{H}_{2} \mathrm{O}$, [Zn $\left.\left(\mathrm{OOCCH}_{3}\right)_{2} \odot 2 \mathrm{H}_{2} \mathrm{O}\right]$ and $\mathrm{CaCl}_{2} \cdot 2 \mathrm{H}_{2} \mathrm{O}$ were obtained from Aldrich and used without further purification. The common laboratory apparatus used were chemical balance, magnetic stirrer, pipettes of different dimensions, filter papers, beakers and petri dishes.

\section{Methods}

\section{Synthesis of MOFs}

The hydro/solvothermal method was used for the synthesis of the compounds. In a typical synthesis, $\mathrm{Cu}\left(\mathrm{NO}_{3}\right)_{2} .2 .5 \mathrm{H}_{2} \mathrm{O}(0.236 \mathrm{~g}$, $1.0 \mathrm{mmol}$ ) was stirred together with benzene tricarboxylic acid (BTC) $(0.210 \mathrm{~g}$, $1.0 \mathrm{mmol}$ ) in $10 \mathrm{~cm}^{3}$ of distilled water. This was followed by the addition of $0.030 \mathrm{~g}$ of 4 , 4-bipyridine and the $\mathrm{pH}$ of the solution was adjusted to 6.0 by the addition of $4.0 \mathrm{~cm}^{3}$ of $0.5 \mathrm{M} \mathrm{NaOH}$. The resulting mixture was homogenized for $30 \mathrm{~min}$ at room temperature before being transferred into a reaction vessel and heated at $120^{\circ} \mathrm{C}$ for $48 \mathrm{~h}$. The bluish green crystalline product was filtered under vacuum, washed with distilled water and air dried. Similar 
procedure was used for compounds 2 (Zn $\left.\left(\mathrm{OOCCH}_{3}\right)_{2} \cdot 2 \mathrm{H}_{2} \mathrm{O}: 0.238 \mathrm{~g}, 1.0 \mathrm{mmol}\right)$ and 3 $\left(\mathrm{CaCl}_{2} \cdot 2 \mathrm{H}_{2} \mathrm{O}: 0.221 \mathrm{~g}, 1.0 \mathrm{mmol}\right)$. The products were characterized with the help of infrared and UV-Vis spectroscopic techniques. Compound 1 was further characterized using SEM and TEM while the structure of compound $\mathbf{3}$ was determined using single-crystal X-ray crystallography.

\section{Conversion of [Cu (HBTC) $\left.\left(\mathrm{H}_{2} \mathrm{O}\right)\right] \cdot \mathrm{H}_{2} \mathrm{O}$ to CuO nanoparticles}

The copper-oxide nanostructures embedded in carbon matrix was carried out by direct calcination of the synthesized CuMOFs as precursor. In a typical process, [Cu (BTC) Bipy] (0.147 g) was taken into crucible and heated in a tube furnace from room temperature to $400{ }^{\circ} \mathrm{C}$ under air to carbonize the MOF. The products were cooled to room temperature and were further characterized by SEM / EDAX and TEM.

\section{Characterization}

Electronic absorption spectra were recorded at ambient temperature on a "Thermo Scientific Evolution 201 UV-Vis spectrophotometer. A portion $\left(1 \mathrm{~cm}^{3}\right)$ of methanolic solution of the compounds $(0.1 \mathrm{~g}$ of solid dissolved in $5 \mathrm{~cm}^{3}$ of methanol) was taken out and dispersed in $5 \mathrm{~cm}^{3}$ of distilled water for the UV-Vis measurement. The Infrared spectra were recorded on a
Shimadzu IR affinity-1 from $400-4000 \mathrm{~cm}^{-1}$. The surface morphology of the as synthesized compound $\mathbf{1}$ and the derived copper oxide nanoparticles embedded in carbon matrix were determined using a Hitachi S-4800 microscope at a voltage of 15 $\mathrm{kV}$. The elemental composition of the $\mathrm{CuO}$ was determined with the help of energy dispersive analysis by x-ray attached to the scanning electron microscope. Transmission electron microscopy (TEM) measurements were performed on a JEOL 1010 instruments at $200 \mathrm{kV}$.

\section{Results and Discussion}

In the synthesis of MOFs, 1, 3, 5benzenetricarboxilic acid (BTC) has been used as an organic linker with different metal ions. For instance, Copper (II) ions in combination with BTC form several different materials depending on the protonation state of the incorporated linker $[29,30]$. One of the major challenges within the field of MOFs is the control of dimensionality [31-35]. When polyfunctional ligands are employed low dimensionality will be formed due to ancillary ligation of the water or other solvent molecules [36]. For example, in the reaction between $\mathrm{Cu}^{2+}$ and $\mathrm{BTC}$ one dimensional chain polymers [Cu(BTC$\left.\mathrm{H})\left(\mathrm{H}_{2} \mathrm{O}\right)_{3}\right] \mathrm{n}$ or $\left[\mathrm{Na} \mathrm{Cu}(\mathrm{BTC})\left(\mathrm{H}_{2} \mathrm{O}\right)_{5}\right]$ are formed from alcoholic solutions at room 
temperature (RT). The same reaction in ethanol resulted in producing 3D HKUST-1 at higher temperatures [37].

When it comes to STAM-1 the same conditions made a $2 \mathrm{D}$ solid with the only difference being the choice of alcohol, from ethanol to methanol. Since the original synthesis of HKUST-1, there have been many variants on the preparative procedure and it is clear that the facile synthesis of HKUST-1 is one of its advantages. Mohideen [38], was able to isolate a new MOF with unique properties by small modification to the synthesis procedure of HKUST-1. The common solvent used for the preparation of HKUST-1 is 50:50 ethanol: water. However, changing the solvent to a 50:50 methanol: water mix resulted in the formation of a new material with the composition $\mathrm{Cu}\left(\mathrm{C}_{10} \mathrm{H}_{6} \mathrm{O}_{6}\right)$ $\left(\mathrm{H}_{2} \mathrm{O}\right) .1 .66 \mathrm{H}_{2} \mathrm{O}$, and named as STAM-1 (St Andrews MOF-1). In this study, BTC was used as an organic linker to complex with three different metal ions namely: $\mathrm{Cu}^{2+}, \mathrm{Zn}^{2+}$ and $\mathrm{Ca}^{2+}$. In a typical synthesis of $\mathbf{1}$, the molar composition: $\mathrm{Cu}\left(\mathrm{NO}_{3}\right)_{2}$ : BTC: 4, 4Bipy: $\mathrm{NaOH}: \mathrm{H}_{2} \mathrm{O}$ was utilized. In the case of compounds $\mathbf{2}$ and $\mathbf{3}$, the compositions were ZnOAc: BTC: 4, 4-Bipy: $\mathrm{H}_{2} \mathrm{O}$ and $\mathrm{CaCl}_{2} \cdot \mathrm{H}_{2} \mathrm{O}$ : BTC: $\mathrm{NaOH}:$ 2, 2-dipyridyl: $\mathrm{H}_{2} \mathrm{O}$ : n-Butanol, respectively. It is worthy of note that the 4 , 4-Bipy and 2, 2-dipyridyl were not incorporated in the final products formed, but assisted the formation of crystals.

Table 1. Infrared vibrational frequencies of the as-synthesized compounds 1-3 $\left(\mathrm{cm}^{-1}\right)$

\begin{tabular}{|c|c|c|c|c|c|c|c|c|}
\hline & $\boldsymbol{v}_{(\boldsymbol{O}-\mathrm{H})}$ & $v_{s y m}(C-H)$ & $v_{\text {asym }}\left(\mathrm{CO}_{2}\right)$ & $v_{s y m}\left(\mathrm{CO}_{2}\right)$ & $\begin{array}{c}\Delta \\
v_{\text {asym }}\left(\mathrm{CO}_{2}\right)- \\
v_{\text {sym }}\left(\mathrm{CO}_{2}\right) / \\
\text { Bonding } \\
\text { mode } \\
\end{array}$ & $\begin{array}{c}\delta(\mathrm{C}-\mathrm{H}) \\
\text { In-plane }\end{array}$ & $\begin{array}{l}\delta(\mathrm{C}-\mathrm{H}) \\
\text { Out-of- } \\
\text { plane }\end{array}$ & $v_{(M-0)}$ \\
\hline \multirow[t]{3}{*}{1} & 3512 & 3080 & 1699 & 1446 & \multirow{3}{*}{$\begin{array}{l}253 \text { Bridging } \\
245 \text { Bridging } \\
285 \text { Unidentate }\end{array}$} & \multirow{3}{*}{$\begin{array}{l}1186 \\
1094\end{array}$} & \multirow{3}{*}{$\begin{array}{l}923 \\
705\end{array}$} & 555 \\
\hline & & \multirow[t]{2}{*}{2889} & 1606 & 1361 & & & & 474 \\
\hline & & & 1573 & 1288 & & & & \\
\hline \multirow[t]{3}{*}{2} & 3512 & 3109 & 1699 & 1425 & \multirow{3}{*}{$\begin{array}{l}274 \text { Unidentate } \\
252 \text { Bridging } \\
300 \text { Unidentate }\end{array}$} & \multirow{3}{*}{$\begin{array}{l}1136 \\
1099\end{array}$} & 893 & 597 \\
\hline & & \multirow[t]{2}{*}{3097} & 1606 & 1354 & & & 682 & 478 \\
\hline & & & 1544 & 1244 & & & & \\
\hline \multirow[t]{3}{*}{3} & 3535 & 3064 & 1681 & 1435 & \multirow{3}{*}{$\begin{array}{l}246 \text { Bridging } \\
220 \text { Chelating } \\
268 \text { Unidentate }\end{array}$} & \multirow{3}{*}{$\begin{array}{l}1199 \\
1112\end{array}$} & 927 & 472 \\
\hline & & \multirow[t]{2}{*}{2980} & 1606 & 1386 & & & 678 & 435 \\
\hline & & & 1533 & 1265 & & & & \\
\hline
\end{tabular}




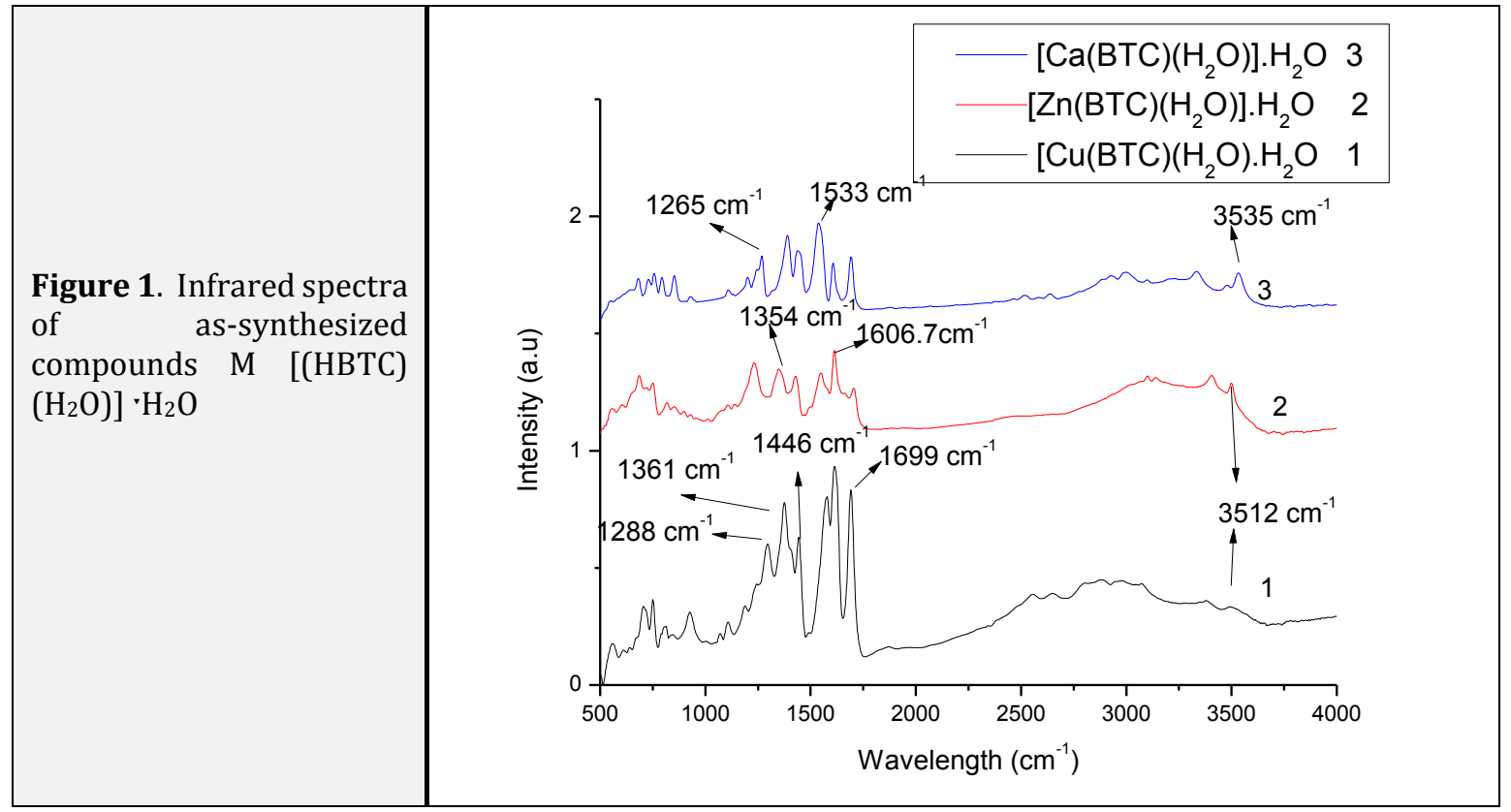

The infrared vibrational frequencies of the three compounds are shown in Table 1, while their FTIR spectra are presented in Figure 1 . The bands for the carboxylate ligand at 1699-1573 (1), 1699-1544 (2) and 1681-1533 $\mathrm{cm}^{-1}$ (3) for asymmetric vibrations and 1446-1288 (1), 1425-1244 (2) and 1435-1265 $\mathrm{cm}^{-1}$ (3) for the symmetric vibrations having separation $\Delta\left[v_{\text {asym }}\left(\mathrm{CO}_{2^{-}}\right)-v_{\text {sym }}\left(\mathrm{CO}_{2^{-}}\right)\right]$values of $245-285$ $\mathrm{cm}^{-1}$ (1), 252-300 $\mathrm{cm}^{-1}(2)$ and $220-268 \mathrm{~cm}^{-1}$ (3) are higher compared to the free carboxylate group and is a good indication that the carboxylate is coordinated with metal atom in a unidentate, chelating and/or bridging fashion [39]. The bands at 1288, 1244 and $1265 \mathrm{~cm}^{-1}$ for compounds 1,2 and 3 , respectively, are assigned to symmetric stretching unidentate $\mathrm{O}-\mathrm{C}-\mathrm{O}$ vibrations. The presence of absorption bands at $1699 \mathrm{~cm}^{-1}$ in 1 and 2, (1681 cm-1 in 3) can be attributed to $-\mathrm{COOH}$ of the tricarboxylates. The bands at $3080-2889 \mathrm{~cm}^{-1}$ in $1,3109-3097 \mathrm{~cm}^{-1}$ in 2 and $3064-2980 \mathrm{~cm}^{-1}$ in 3 are due to $\mathrm{C}-\mathrm{H}$ stretch of the benzene ring. The in-plane $\mathrm{C}-\mathrm{H}$ bending vibrations of the $1,3,5$ trisubstituted benzene ring are observed at $1186-1094 \mathrm{~cm}^{-1}$ in $1,1136-1099 \mathrm{~cm}^{-1}$ in 2 and $1199-1112 \mathrm{~cm}^{-1}$ in 3, while the out-ofplane $\mathrm{C}-\mathrm{H}$ bending vibrations appeared in the region $923-705 \mathrm{~cm}^{-1}, 893-682 \mathrm{~cm}-1$ and 927-678 $\mathrm{cm}^{-1}$ for compounds 1,2 and 3 , respectively. Bands in the region 555-474 $\mathrm{cm}^{-1}$ in $1,597-478 \mathrm{~cm}^{-1}$ in 2 and 472- 435 $\mathrm{cm}^{-1}$ in 3 are due to M-O vibrations. The bands at 3477,3495 and $3523 \mathrm{~cm}^{-1}$ for 1,2 and 3 , respectively, are attributable to 0 $\mathrm{H}$ stretching vibrations. 
The electronic spectrum of [Cu (HBTC) $\left.\left(\mathrm{H}_{2} \mathrm{O}\right)\right] \cdot \mathrm{H}_{2} \mathrm{O} \quad \mathbf{1}$, in methanol solution presented in Figure 2, exhibits a unique band at $511 \mathrm{~nm}$. In the region $520-534 \mathrm{~nm}$, the band splits into two moderately intense peaks at 527 and $531 \mathrm{~nm}$. These absorption peaks along with another band at $538 \mathrm{~nm}$ are assigned to $d-d$ transitions of the copper (II) ion. This type of $d-d$ spectrum is typical of a distorted square planar arrangement around the copper (II) ion [40, 41].

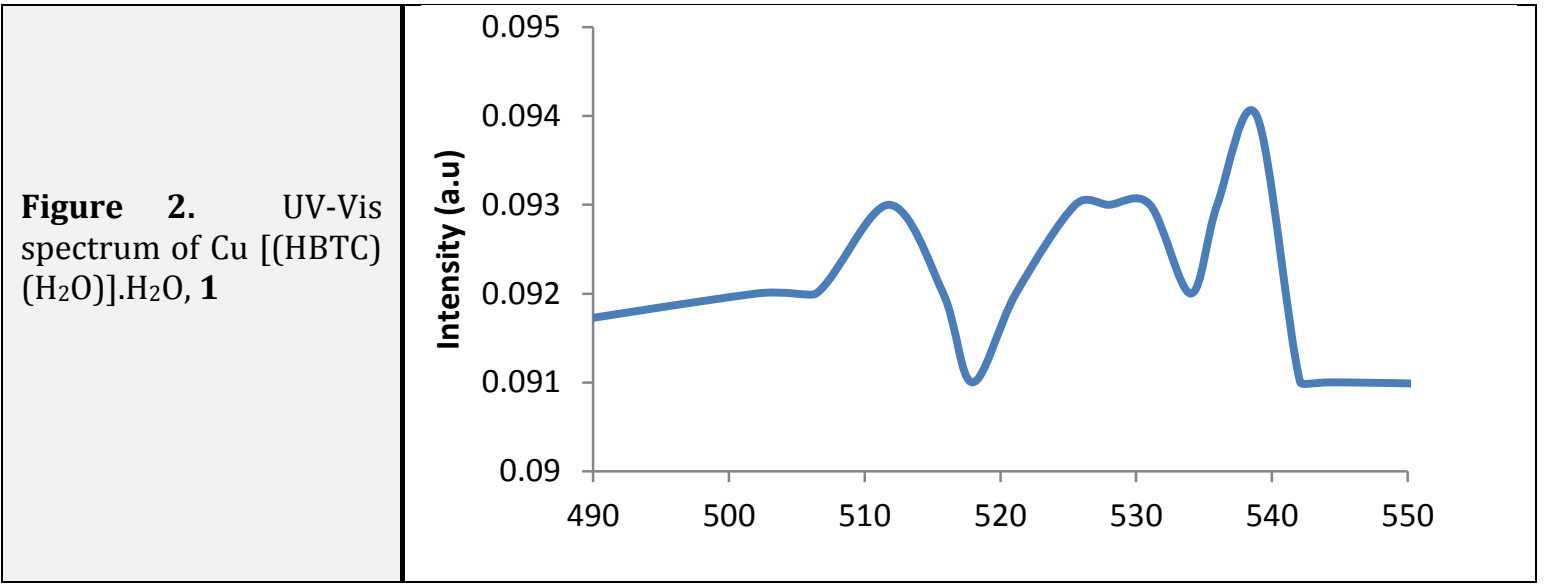

Scheme 1.

Coordination environment of benzenetricarboxylic acid

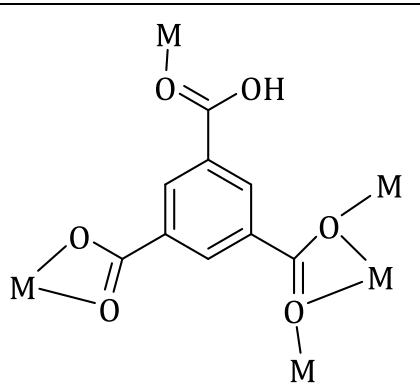

Figure 3. Well-ordered structure with BTC ligand linking the individual chains to form a network structure

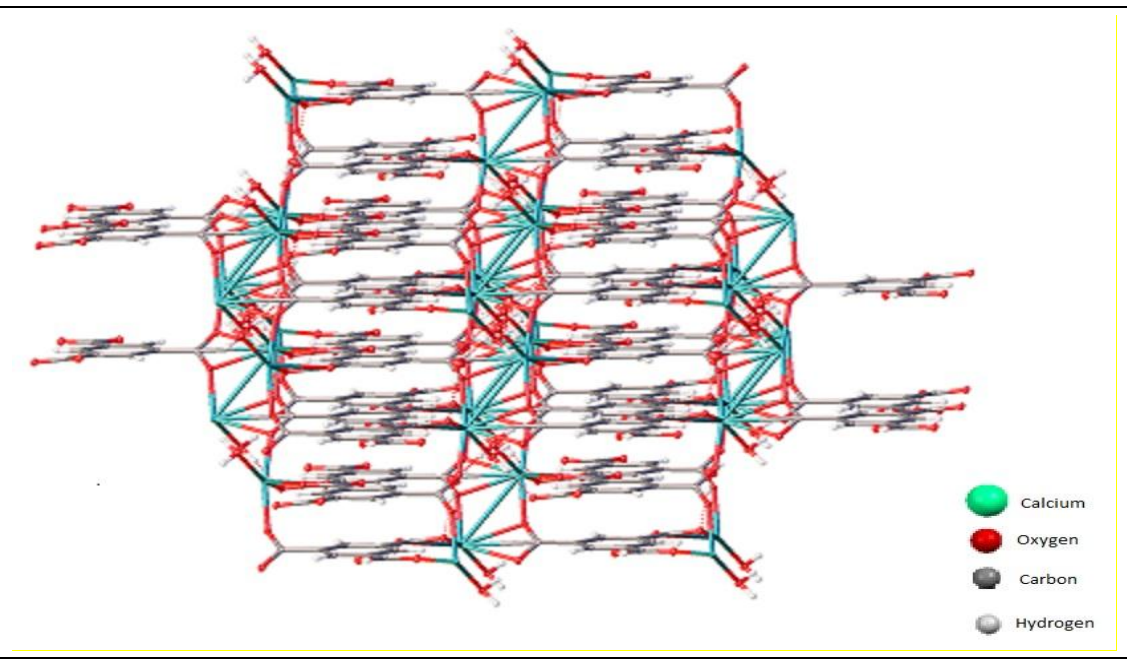


Single-crystal x-ray crystallographic studies of $\left[\mathrm{Ca}(\mathrm{HBTC})\left(\mathrm{H}_{2} \mathrm{O}\right)\right] \cdot \mathrm{H}_{2} \mathrm{O}, 3$, revealed that it crystallizes in a triclinic crystal system with the following cell dimensions: $\mathrm{a}=6.8325(13)$ $\mathrm{b}=8.9345(17), \quad \mathrm{c}=9.9752(19) \quad \AA, \quad \alpha=$ 102.119(2), $\beta=100.791(2), \gamma=109.701(2)^{\circ}$. The asymmetric unit consists of one crystallographically independent calcium (II) ion, a BTC2- anion, aqua ligand and lattice water. Calcium is coordinated to seven carboxylate oxygen atoms from one BTC ligand and one oxygen from aqua ligand to form a $\mathrm{CaO}_{8}$ polyhedra. The BTC ligand is heptadentate coordinating to Ca atom via 01 and 02 in a chelating and bidentate bridging fashion, through 03 and 04 in a chelating mode and through 05 in a unidentate mode (Scheme 1). The edge-sharing of $\mathrm{CaO}_{8}$ polyhedra along $a$-direction gives rise to inorganic chain that are connected by the BTC ligands to form a three dimensional framework with water molecules in the channels (Figure 3). The Ca-O bond distances are in the range of 2.4030 (3) -
2.5655(4) Å and are consistent with similar compounds in the literature $[38,39,41]$.

The copper-based MOF, compound 1, was converted into copper oxide nanostructures embedded in carbon matrix by heating to a temperature of $400{ }^{\circ} \mathrm{C}$ in air. The energy dispersive analysis of the calcined product (Figure 4) gives the composition of copper, oxygen and carbon as 61.52, 20.30 and $18.18 \%$, respectively.

The representative SEM image of the CuMOFs and $\mathrm{CuO}$ nanostructures are presented in Figure 5. The image of copperbased MOFs shows the presence of rod-like crystals whereas the copper oxide derived from the MOFs consists of microspheres with average size of $2.5 \mu \mathrm{m}$, The TEM images of the as-synthesized MOF and the CuO Nano are presented in Figure 6. The TEM image of the as-synthesized CuMOFs reveals the presence of Nano-rod crystals, while the image of the derived copper oxide shows uniform Nano spheres of $10-100 \mathrm{~nm}$ size.

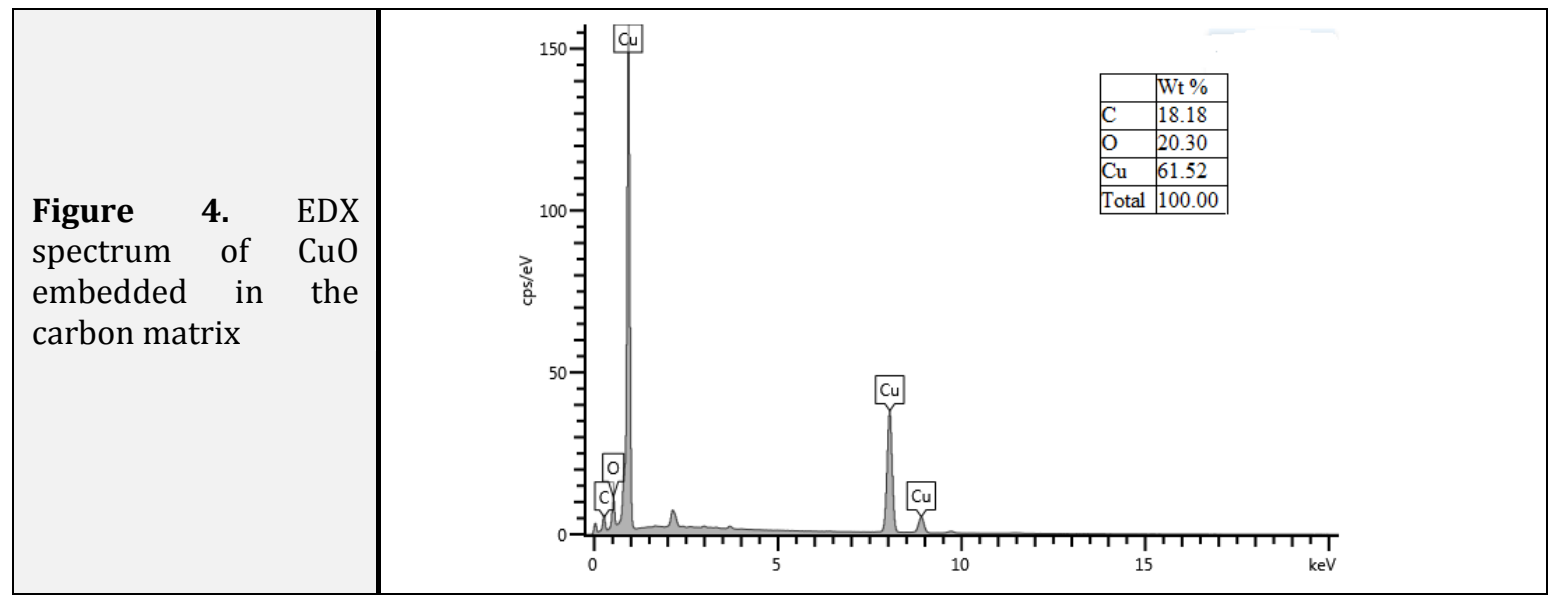



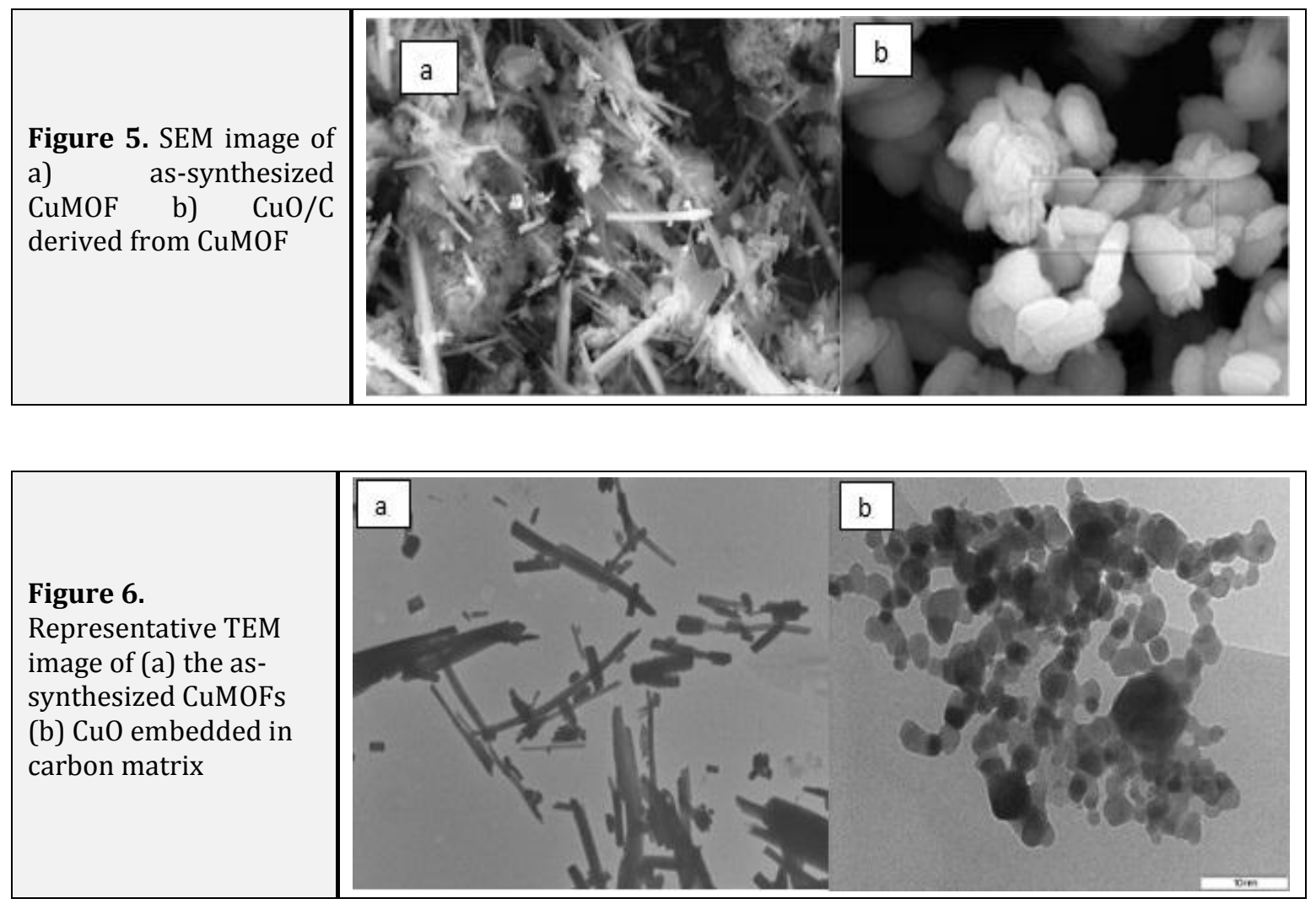

\section{Conclusion}

Three metal-organic framework materials: $\mathrm{M}$ [(HBTC) $\left.\left(\mathrm{H}_{2} \mathrm{O}\right)\right]^{\prime} \mathrm{H}_{2} \mathrm{O}(\mathrm{M}=\mathrm{Cu}, \mathrm{Zn}$ and $\mathrm{Ca})$ constructed with 1, 3, 5-benzene tricarboxylate have been synthesized under hydro/solvothermal conditions and characterized using spectroscopic techniques and x-ray diffraction method. Using $\mathrm{Cu}-\mathrm{MOF}$ as a precursor material, copper oxide nanoparticle embedded in carbon matrix has been synthesized by simply heating in air to $400{ }^{\circ} \mathrm{C}$. The SEM, TEM, and EDS measurements confirmed that copper oxide nanoparticles have been formed in the carbon matrix. Research is underway on the properties and applications of the MOF-derived metaloxide nanomaterials as catalysts and sensors and will be published elsewhere.

\section{Acknowledgement}

This work was supported by The World Academy of Sciences for the Advancement of Science in developing countries (TWAS) under Research Grant No 12-169 RG/CHE/AF/AC-G UNESCO FR: 3240271320 for which grateful acknowledgment is made. A.A.A is also grateful to the Royal Society of Chemistry for personal Research grant. We thank Professor Arnie Rheingold of the Department of Chemistry and Biochemistry, University of California, San Diego for 
Single-Crystal X-ray crystallographic data.

\section{References}

[1]. M. Fernández-Garcia, J.A. Rodriguez, and Encyclopedia of Inorganic and Bioinorganic Chemistry: Metal Oxide Nanoparticles; John Wiley \& Sons, Ltd: New York, NY, USA. 2011, pp. 1-3.

[2]. Y. Teow, P.V. Asharani, M.P. Hande, S. Valiyaveettil, Chem. Communic., 2011, 47, 7025-7038.

[3]. C. Noguera. Physics and chemistry at oxide surfaces; Cambridge University Press, Cambridge, UK, 1996.

[4]. H.H. Kung. Transition Metal Oxides: Surface Chemistry and Catalysis; Elsevier, Amsterdam, 1989.

[5]. V.E. Henrich, P.A. Cox. The surface chemistry of metal oxides; Cambridge University Press, Cambridge, UK, 1994.

[6]. J.A. Rodríguez, M. Fernández-García, Synthesis, Properties and Applications of Oxide Nanoparticles. Wiley, New Jersey, 2007.

[7]. H. Gleiter. Nanostruct. Mater., 1995, 6, 314.

[8]. M. Valden, X. Lai, D.W. Goodman. Science, 1998, 281, 1647.

[9]. J.A. Rodriguez, G. Liu, T. Jirsak, C. Z. Hrbek, J. Dvorak, A. Maiti. J. Am. Chem. Soc., 2002, 124, 5242-5250.

[10]. W. Bak, H. S. Kim, H. Chun, W. C. Yoo. Chem. Commun., 2015, 51, 7238-7241.
[11]. M.S. Kang, D.H. Lee, K.J. Lee, H.S. Kim. J. Ahn, Y.E. Sung, W.C. Yoo. New J. Chem., 2018, 42, 18678-18689 DOI: 10.1039/CBNJ04919 [12]. X. Sun.J. Dispers. Sci. Technol., 2003, 24, 557-567.

[13]. S. Miyanaga, H. Yasuda, A. Hiwara, A. Nakumura, H. Sakai, J. Macromolecular Sci. Part. A Chem., 1990, 27, 1347-1361.

[14]. H. Li, M. Eddaoudi, M. O’Keeffe, O.M. Yaghi. Nature, 1999, 402, 276-279.

[15]. X. Lin, I. Telepeni, A.J. Blake, A. Dailly, C.M. Brown, J.M. Simmons, M. Zoppi, G.S. Walker, K.M Thomas, T.J. Mays, P. Hubberstey, N.R. Champness, M.

Schroder. J. Am. Chem. Soc., 2009, 131, 2159 $-2171$

[16]. J.R. Li, R.J. Kuppler, H.C. Zhou. Chem. Soc. Rev. 2009, 38, 1477-1504.

[17]. J.R. Li, J. Sculley, H.C. Zhou, Chem. Rev. 2012, 112, 869-932.

[18]. B.E. Inah, A.A. Ayi, A. Adhikary. Acta Cryst., 2017, E73, 246-249.

[19]. D. Zhang, Y. Yang, Z. Wu, G. Dong, Sensor. Actuators B: Chem., 2019, 283, 42-51 [20]. W. Yang, X. Li, Y. Li, R. Zhiu, H. Pang, Adv. Mater., 2019, 31, 1804740 https://doi.org/10.1002/adma.201804740. [21]. X. Cao, L. Cui, B. Liu, Y. Liu, D. Jia, W. Yang, J. M. Razal, J. Liu. J. Mater. Chem. A, 2019, 7, 3815-3827.

[22]. J.J. Chen, Y.T. Chen, D. S. Raja, Y.H. Kang, P.C. Tseng, C.H. Lin. Materials, 2015, 8, 5336- 
5347.

[23]. R. Das, P. Pachfule, R. Banerjee, P.

Poddar, Nanoscale, 2012, 4, 591-599.

[24]. L. Hu, Q. Chen. Nanoscale, 2014, 6, 1236-1257.

[25]. J.K. Sun, Q. Xu. Energy \& Environ. Sci., 2014, 7, 2071-2100.

[26] B. Liu, H.C. Zeng. J. Am. Chem. Soc., 2004, 126, 8124-8125.

[27]. B. Liu, H. Shioyama, T. Akita, Q. Xu, J. Am. Chem. Soc., 2008, 130, 5390-5391.

[28]. Y. Liu, Y. Chu, Y. Zhuo, M. Li, L. Li, L. Dong. Cryst. Growth Des., 2007, 7, 467-470. [29]. R. Pech, J. Pickardt. Acta Crystallogr. C, 1988, 44, 992-994.

[30]. S.S. Chui, S.M. Lo, J.P., Charmant, A.G. Orpen, I.D. Williams, Science, 1999, 283. 1148-1150.

[31]. N. Stock, S. Biswas, Chem. Rev., 2012, 112, 933-969.

[32]. S.T. Meetk, J.A. Greathouse, M.D. Allendorf, Adv. Mater., 2011, 23, 249-267

[33]. S.L. James. Chem. Soc. Rev. 2003, 32, 276-288
[34]. O.M. Yaghi, M. O'Keeffe, N.W. Ockwig, H. K. Chae, M. Eddaoudi, J. Kim, Nature, 2003, 423,705-714.

[35] S. Kitagawa, R. Kitaura, S.I. Noro, Angew. Chem. Int. Ed. 2004, 43, 2334-2375. [36]. F.A.A. Paz, J. Klinowski. Pure Appl. Chem., 2007, 79, 1097-1110.

[37]. S.S.Y. Chui, A. Siu, I.D. Williams. Acta Cryst. C., 1999, 55, 194-196.

[38]. M.I.H. Mohideen. Novel metal organic frameworks: synthesis, characterization and functions. A Thesis Submitted for the Degree of $\mathrm{PhD}$ at the University of St. Andrews: http://hdl.handle.net/10023/1892.

[39]. G.B.Deacon, R.J. Phillips, Coordin. Chem. Rev., 1980, 33, 227-250

[40]. N. Gupta, R. Gupta, S. Chandra, S.S. Bawa, Spectrochim. Acta A, 2005, 61, 11751180.

[41]. R.K.Vakiti. Hydro/Solvothermal Synthesis, Structures and Properties of Metal-Organic Frameworks Based on SBlock Metals. Masters Theses \& Specialist Projects. Paper 1168. 2012.

How to cite this manuscript: Chinyere A. Anyama, Providence B. Ashishie, Bassey E. Inah, Idongesit J. Mbonu, Ayi A. Ayi*, Metal-Organic Frameworks as Precursor for Metal Oxide Nanostructures Part I: MOF-Derived Copper Oxide Embedded in Carbon Matrix, Advanced Journal of Chemistry-Section A (Adv. I. Chem. A), 2019, 2(3), 234-244. 